Erratum

\title{
Corrigendum to "serum thiamine concentration and oxidative stress as predictors of mortality in patients with septic shock" [J Crit care 2014;29(2):249-52]
}

Nara Aline Costa ${ }^{\mathrm{a}}$, Ana Lúcia Gut ${ }^{\mathrm{a}}$, Mariana de Souza Dorna ${ }^{\mathrm{a}}$, José Alexandre Coelho Pimentel ${ }^{\mathrm{b}}$, Silvia Maria Franciscato Cozzolino ${ }^{b}$, Paula Schmidt Azevedo ${ }^{a}$, Ana Angélica Henrique Fernandes ${ }^{c}$, Leonardo Antonio Mamede Zornoff ${ }^{a}$, Sergio Alberto Rupp de Paiva ${ }^{a}$, Marcos Ferreira Minicucci ${ }^{\mathrm{a}, *}$

a Department of Internal Medicine, Botucatu Medical School, UNESP - Univ Estadual Paulista, Botucatu, Brazil

${ }^{\mathrm{b}}$ Department of Food and Experimental Nutrition, Faculty of Pharmaceutical Science, University of São Paulo, São Paulo, Brazil

c Chemistry and Biochemistry Department, Institute of Biological Sciences, UNESP - Univ Estadual Paulista, Botucatu, Brazil

The authors reviewed the data and regret that the results of protein carbonyl in Table 1 are inverted. However, the discussion and conclusion are correct. The correct form is inserted below:

The authors would like to apologize for any inconvenience caused.

Table 1

Demographical, clinical and laboratorial data of 108 patients with septic shock

\begin{tabular}{llll}
\hline Variable & Hospital mortality & \\
\cline { 2 - 3 } & Yes $(\mathrm{n}=68)$ & No $(\mathrm{n}=40)$ \\
\hline Protein carbonyl, $(\mathrm{nmol} / \mathrm{ml})$ & $13.8(5.1-25.7)$ & $5.3(3.3-22.3)$ \\
\hline
\end{tabular}

DOI of original article: http://dx.doi.org/10.1016/j.jcrc.2013.12.004.

* Corresponding author at: Department of Internal Medicine, Botucatu Medical School, UNESP-Univ Estadual Paulista, Botucatu, Brazil.

E-mail address: minicucci@fmb.unesp.br (M.F. Minicucci). 